\title{
Mistletoe and Immunomodulation: Insights and Implications for Anticancer Therapies
}

\author{
Shiao Li Oei $\mathbb{D}^{1}$, Anja Thronicke ${ }^{1}$, and Friedemann Schad $\mathbb{D}^{1,2}$ \\ ${ }^{1}$ Research Institute Havelhöhe, 14089 Berlin, Germany \\ ${ }^{2}$ Oncological Centre, Hospital Havelhöhe, 14089 Berlin, Germany \\ Correspondence should be addressed to Shiao Li Oei; shiaoli.oei@havelhoehe.de
}

Received 21 September 2018; Revised 20 March 2019; Accepted 14 April 2019; Published 17 April 2019

Guest Editor: Hyo-jin An

Copyright (c) 2019 Shiao Li Oei et al. This is an open access article distributed under the Creative Commons Attribution License, which permits unrestricted use, distribution, and reproduction in any medium, provided the original work is properly cited.

\begin{abstract}
In early tumor development, cancer cells develop a plethora of strategies to escape surveillance from the adaptive and innate immune system. Cancer immunotherapies, in particular immune checkpoint inhibitors, are becoming a highly promising cancer therapeutic approach that has remarkable increased progress in combating various cancer types. Unfortunately, their mechanisms of action induce some complications, such as inflammatory reactions and immune-related adverse events. In the management of side effects during anticancer therapy, complementary and integrative therapy approaches are becoming of growing interest. Particularly, mistletoe, Viscum album L. (VA), has a long traditional history of about 100 years as an add-on therapy of cancer treatment in German-speaking countries. Besides antitumoral and quality of life-promoting activities, VA applications reduce side effects of modern conventional anticancer therapies and exert immunomodulatory characteristics. As these properties may provide a good basis for a combination with modern oncological therapies, the biological activities of VA applications and mechanisms involved have to be understood. In this review, the impact of VA compounds on different cellular pathways and immunological reactions in the fight against cancerous cells is discussed.
\end{abstract}

\section{Cancer Immunotherapy}

Cancer cells are able to gain control over a number of inhibitory pathways that are important for controlling immune responses and a major challenge of cancer therapy is to overcome immune resistance promoting tumor survival [1, 2]. The interplay between tumors and the immune system has long been known to involve complex interactions between tumor cells, immune cells, and the tumor microenvironment. For example, gain of expression of immunoinhibitory molecules such as programmed cell death protein 1 (PD-1) or altered expression of components involved in apoptosis is leading to apoptotic resistance. Considering different signaling pathways and strategies to overcome immunosuppression and to enhance the immunogenicity of tumors (by reverting their immune escape), various immunotherapies have been developed. A very promising approach led recently to the design of immune checkpoint inhibitors (ICIs), which in the meantime have increasingly been studied and used as a successful therapy for the treatment of various tumor types [3]. The immune checkpoint proteins cytotoxic Tlymphocyte-associated-4 (CTLA-4) and PD-1 are receptors, expressed on the surface of cytotoxic T-cells, which interact with their specific ligands (CD80/CD86 and PD-L1, resp.). These pathways can be exploited by cancer cells to escape from T-cell-mediated cell death [4]. Despite the significant benefits of ICIs, these drugs affect multiple organ systems, and their use can be associated with immune-related adverse events such as inflammatory arthritis, myositis, vasculitis, alveolitis, and further syndromes, which require appropriate long-term management [5]. Generally, clinical efficacy of anticancer therapy often is accompanied by side effects that affect the patient's quality of life and can lead to treatment discontinuations. Therefore, there is a considerable interest for supportive therapies counteracting toxicities without interfering with the elimination of cancerous cells. Another strategy to stimulate T-cells against tumor-specific epitopes is the development of therapeutic vaccines. These interventions include the identification of appropriate tumor antigens as targets for therapy [6]. The specificity of therapeutic 
vaccination combined with immunomodulation offers an attractive avenue for the development of cancer therapies. In comparison with clinical results of ICIs, vaccines have been less impressive; nevertheless, some combinations of ICIs with vaccines treatment seem to be promising for certain cancer diseases [7]. Furthermore, in most recent studies with oncolytic viruses combined with ICI therapy, it was suggested that antiviral immunological events may inflame the tumor and make it "hot" and suitable for subsequent ICI treatment [8]. Thus, combinational strategies could present an attractive opportunity for fighting cancer in the future.

\section{Viscum Album Extracts and Immunomodulation}

Mistletoe, Viscum Album L. (VA), therapy as an add-on therapy is among the most frequently used integrative oncological drugs in several countries in Europe [24]. Aims of add-on VA therapy are the improvement of health-related quality of life and the reduction of adverse events (AEs) associated with conventional anticancer strategies and, additionally, various immunomodulating activities have been described [25, 26]. The elucidation of immunostimulatory mechanisms of VA preparations and further validations in the context of clinical studies are critical in understanding the importance of addon VA therapy. VA extracts contain a variety of compounds including mistletoe lectins and viscotoxins which have been ascribed to exert immunomodulatory effects [27]. Here, we discuss the impact of VA extracts between the immune system and cancer. Considering the abundance of published findings on this topic, we focus on preclinical and clinical findings in the context of primary effects of VA extracts on human immunological pathways. In a clinical study with 43 healthy volunteers, it was observed that, in an immediate response to a subcutaneous VA application, the numbers of leukocytes, granulocytes, and eosinophil cells increased [9]. Furthermore, the impact of VA extracts on the functionality of T-lymphocytes was studied. In a placebo-controlled trial with 71 healthy subjects, it was observed that subcutaneous applications of VA extracts resulted in eosinophilia and an increase of CD4 T-lymphocytes [10]. In addition, the specific immune system is also activated, as evident from the production of specific antibodies raised against VA lectins and viscotoxins, demonstrated in a randomized controlled trial with 47 healthy volunteers [11]. In a clinical study with eight cancer patients after application of VA extracts, the cytokine levels in serum increased [12]. In another clinical study with 10 breast cancer patients, after subcutaneous injections of VA lectins, a stimulation of natural killer (NK) and T-helper cells was detected [14]. Immunization experiments with mice showed that lectins are potent immunoadjuvants to enhance cellular and humoral immune responses [18]. In a study with cultured tumor cells, Korean mistletoe lectins exhibited immunomodulatory properties by enhancing dendritic cell maturation [22]. A maturation-inducing effect on human dendritic cells by application of VA extracts was shown in an in vitro study using a human cellular system [23].

After administration of VA extracts to tumor patients, the numbers of lymphocytes and NK cells increased [13].
In cultured glioblastoma cells, VA extracts inhibited tumor growth and enforced NK cell-mediated lysis of glioblastomas [16]. Several immunomodulatory effects in response to a single intravenous infusion of VA extracts such as neutrophilia, enhancement of phagocytic activity of granulocytes, and increase of $\mathrm{NK}$ cells have been reported [15]. NK cells play an important role in antitumoral immunity as they mediate the elimination of tumor cells and regulate the adaptive immunity. Cell experimental analyses revealed that viscotoxins are responsible for the increase in NK cellmediated cytotoxicity [17]. In a clinical study of 70 cancer patients, it was observed that perioperative VA applications during digestive surgery increased the number of NK cells, in particular T-helper cell counts [19], and in a study with 98 breast cancer patients, a prevention of surgery-induced inhibition of the oxidative burst in granulocytes by intravenous application of VA extracts was shown [20]. A clinical trial with 62 colorectal cancer patients revealed that VA extracts can prevent suppression of NK cell activities [21]. A summary of the immunological activities of VA applications, which have been derived from preclinical and clinical studies, is given in Table 1.

Against this backdrop, complex immunological crosstalks and synergistic interactions of VA-mediated pathways may be critical for the entire process to eliminate cancerous cells. Due to the complexity of tumor development, it can be expected that addressing different pathways by using combinational treatment procedures may be a promising approach. Modern immunotherapies in combination with add-on VA could therefore be a helpful strategy to achieve synergism in cancer treatment efficacy. One of several wellstudied immunological signaling pathways in which VA is involved is outlined below.

\section{VA and the Cyclooxygenase Signaling Pathway}

Bioactive phytochemicals are able to act as natural immunomodulators [28]. In this regard, a recent review reported that phytochemicals such as polyphenolic substances of green tea may exhibit anti-inflammatory and anticancer effects [29]. For inflammatory reactions, the cyclooxygenases (COX) are critical enzymes for several pathways including cytokine-induced secretion of prostaglandin $\mathrm{E}_{2}$. Some VA preparations were reported to have inflammatory properties and preclinical studies indicated that certain phytochemicals including components derived from VA preparations reduce selectively COX-2 levels [30-32]. COX-1 is constitutively and stably expressed at low levels in many tissues and involved in gastrointestinal, renal, vascular, and other physiological functions. As a result of a cross-talk between several mediators of inflammation, such as interleukins and cytokines, COX-2 is highly induced and its upregulation correlates with a poor cancer prognosis [33]. The COX-2 activity can be regulated at different levels. Various corticosteroids are available to suppress the immune system and reduce inflammatory reactions, but their use can be associated with a variety of side effects [34]. Traditional nonsteroid antiinflammatory drugs (NSAID) inhibit the enzymatic activity 
TABLE 1: Immunological activities of applied VA extracts.

\begin{tabular}{|c|c|c|}
\hline VA-mediated activities & Study type & References \\
\hline $\begin{array}{l}\text { Increase of leukocytes, eosinophils, and } \\
\text { granulocytes }\end{array}$ & $\begin{array}{c}\mathrm{RCT}, \\
\text { placebo-controlled } \\
\text { trial }\end{array}$ & {$[9,10]$} \\
\hline $\begin{array}{l}\text { Induction of specific antibodies against } \\
\text { VA constituents }\end{array}$ & RCT & {$[11]$} \\
\hline Increase of secretion of cytokines & Clinical study & [12] \\
\hline Increase of lymphocytes & Clinical study & [13] \\
\hline $\begin{array}{l}\text { Increase of activity of natural killer (NK) } \\
\text { cells }\end{array}$ & Clinical studies & {$[13-15]$} \\
\hline $\begin{array}{l}\text { Enforcement of NK-cell mediated lysis of } \\
\text { glioblastomas }\end{array}$ & Preclinical study & {$[16]$} \\
\hline $\begin{array}{l}\text { Increase of neutrophils and increase of } \\
\text { granulocyte activity }\end{array}$ & Clinical study & {$[15]$} \\
\hline Increase of activity of NK cells & Preclinical study & {$[17]$} \\
\hline $\begin{array}{l}\text { Enhancement of cellular and humoral } \\
\text { immune response }\end{array}$ & Preclinical study & {$[18]$} \\
\hline $\begin{array}{l}\text { Increase of the activities of NK cells } \\
\text { during surgery }\end{array}$ & $\begin{array}{c}\text { Clinical studies, } \\
\text { RCT }\end{array}$ & {$[19-21]$} \\
\hline Enhancement of dendritic cell maturation & Preclinical study & [22] \\
\hline $\begin{array}{l}\text { Abrogation of tumor-induced } \\
\text { immunosuppression of dendritic cells }\end{array}$ & Preclinical study & {$[23]$} \\
\hline
\end{tabular}

NK: natural killer; RCT: randomized clinical trial; VA: Viscum album L.

of all COX enzymes and this also produces gastrointestinal toxicity, due to the inhibition of production and secretion of physiological prostaglandins. In difference to treatment of occurring AEs with NSAIDs, modern selective COX-2 inhibitors are efficient and showed a better safety profile than do nonselective NSAIDs, but adverse cardiovascular events may occur [35]. When COX-2 inhibitors have to be withdrawn, typically due to the occurrence of cardiovascular side effects, disease-modifying antirheumatic drugs are used to arrest progression of inflammatory reactions and relief from pain; however, these antirheumatics also inhibit other important immunological reactions. Hence, there is a need for anti-inflammatory agents, targeting the control of COX-2 levels but balancing safety and efficacy. Interestingly, for some phytotherapeutics, including VA preparations, it was shown that they influence COX-2 activity. Therefore, it was suspected that these phytochemicals may exert an anti-inflammatory effect via this pathway $[29,36]$. It was shown that VA preparations reduced selectively COX-2 levels [30] and further experiments confirmed that VA preparations have the capacity to downregulate induced COX-2 activities by posttranscriptional destabilization of its transcripts [32]. From a retrospective analysis of medical records of 324 colorectal cancer patients, it was suggested that this proposed VA-mediated mechanism may contribute to alleviating inflammatory activities involved in cancerrelated fatigue [37]. In difference to unspecific downregulation of COX activities by corticosteroids or NSAIDs, this proposed VA-dependent anti-inflammatory mechanism does not interfere with physiological functions, since COX-1 activity is not affected. It was hypothesized that this supportive
VA-associated activity may contribute to various beneficial effects observed in clinical studies [30,38].

\section{Cancer, Immunity, and Safety Concerns}

Numerous efforts have been undertaken to develop ways of stimulating the cellular immune response to eradicate tumors. The progress of checkpoint inhibitors in the clinical setting in the last decade has highlighted again the role of the immune system in the fight against cancer. Immune checkpoint therapy has revolutionized cancer treatment and has fundamentally changed the outcome for certain groups of patients with advanced cancer [3]. However, the application of ICIs is associated with relevant side effects, rarely even with lethal consequences $[39,40]$. Usual treatments of drugrelated AEs are therapy disruption and/or the application of corticosteroids or other immunosuppressant agents [41], which can reduce the signs and symptoms of inflammatory conditions but also have a general suppressing effect on the whole immune system, thus possibly interfering with the body's own defenses against tumor cells. The drug-related AEs of third-generation ICIs are lowered in relation to early developed inhibitors but still may cause severe immune responses, which can occur with a time delay and therefore cannot always be clearly assigned [39, 41]. Moreover, combinations of different ICIs seemed to increase grade 3-4 AEs in cancer patients [42] and also potentiation in toxicities has been seen with ICIs in combination with chemotherapy [39, 43]. Therefore, research and development of treatment strategies to optimize clinical positive outcomes and minimize occurring AEs of cancer patients is a key challenge for the future. 
The cytotoxic and immunomodulatory properties of different VA preparations and applications have been intensively studied in the last years. Add-on VA therapy has been reported to entail a sound safety profile with no serious side effects. VA-associated AEs were reported but appeared to be dose-dependent and primarily confined to reactions at injection site and mild, transient pyrexia and flu-like symptoms [44-47]. Only in rare cases under intravenous VA treatment in a dose-dependent fashion were pseudoallergic hypersensitivity reactions described [48]. Hence, the application of VA extracts exhibits only low risks and seems to be safe but should be monitored by clinicians when applied in high dosages.

VA preparations, which have been shown to reduce AEs of chemo- and radiotherapy in cancer patients [26], may also exert positive effects during targeted therapy. In a randomized phase II study with 72 advanced lung cancer patients, it was observed that chemotherapy dose reductions, grade 3-4 nonhaematological side effects, and hospitalizations occurred less frequently in patients treated with add-on VA [49]. Utilizing registry data of 310 cancer patients, in a recent observational study, we observed a significant reduction of AE-induced treatment discontinuations in cancer patients, when treated with VA applications in addition to targeted therapy [50]. Furthermore, previously we evaluated the clinical safety of ICIs with add-on VA in patients with advanced or metastatic cancer [51]. This pilot observational study indicated that the ICI-induced AE rate was not adversely influenced by concomitant VA therapy. Further observational analyses have suggested that the combined treatment with ICIs and VA might even lower the AE rate including the immune-related AE rate [52]; however, no final conclusion is to be drawn yet due to a small patient number. More clinical trials are needed to characterize VA-mediated reduction of $\mathrm{AE}$ rates and may elucidate whether a combined treatment of ICIs and VA may have synergistic effects for safety-relevant outcomes.

\section{Clinical Relevance and Perspectives}

With the increasing knowledge of molecular signaling pathways and pathological mechanisms involved in progression of cancers, collaborative strategies have to be elaborated to optimize therapeutical outcomes. There is growing evidence that VA substances can exert apoptotic and cytotoxic as well as anti-inflammatory and immunological effects during cancer therapies. Some AEs resulting from anticancer therapies are no life-threatening diseases; however, these AEs may severely affect patients' quality of life and even worse can lead to treatment discontinuations. A reduction of AEs would support the adherence to anticancer therapy and might concurrently improve clinical outcomes of these therapies. In a systematic review of 26 randomized controlled and further 10 nonrandomized trials, the influence of VA extracts on quality of life in cancer patients was evaluated [26]. All the nonrandomized and 22 of the randomized trials reported a benefit and the authors concluded that VA treatments seem to have an impact on quality of life and reduce side effects of conventional therapies such as chemotherapy and radiation [26]. In addition, significant better overall survival was reported in a randomized clinical trial of advanced pancreatic cancer patients treated with VA [53], and the beneficial impact on overall survival was further supported with two recent real-world observational studies of add-on VA-treated advanced or metastasized pancreatic cancer [54] and metastasized non-small cell lung cancer patients [55]. In conclusion, through balanced interactions in complex immunological pathways, VA may assist the elimination of cancerous cells and additionally supports standard oncological strategies by lowering adverse effects. This in turn can exert positive effects on quality of life and might improve tolerability of cancer treatments. An improved patient compliance in cancer treatments may lead to better clinical outcomes. Therefore, it might be promising to further examine how combinational immunomodulating strategies like add-on VA treatment are suited to reduce occurring AEs in immunooncology.

\section{Conflicts of Interest}

Friedemann Schad reports grants from Helixor Heilmittel $\mathrm{GmbH}$, Iscador $\mathrm{AG}$, and ABNOBA GmbH outside the submitted work. All other authors declare that they have no conflicts of interest.

\section{References}

[1] H. O. Alsaab, S. Sau, R. Alzhrani et al., "PD-1 and PD-L1 checkpoint signaling inhibition for cancer immunotherapy: mechanism, combinations, and clinical outcome," Frontiers in Pharmacology, vol. 8, article 561, 2017.

[2] S. G. Kalathil and Y. Thanavala, "High immunosuppressive burden in cancer patients: a major hurdle for cancer immunotherapy," Cancer Immunology, Immunotherapy: CII, vol. 65, no. 7, pp. 813-819, 2016.

[3] S. C. Wei, C. R. Duffy, and J. P. Allison, "Fundamental mechanisms of immune checkpoint blockade therapy," Cancer Discovery, vol. 8, no. 9, pp. 1069-1086, 2018.

[4] J. Dine, R. Gordon, Y. Shames, M. Kasler, and M. BartonBurke, "Immune checkpoint inhibitors: An innovation in immunotherapy for the treatment and management of patients with cancer," Asia-Pacific Journal of Oncology Nursing, vol. 4, no. 2, pp. 127-135, 2017.

[5] A. Sosa, E. Lopez Cadena, C. Simon Olive, N. Karachaliou, and R. Rosell, "Clinical assessment of immune-related adverse events," Therapeutic Advances in Medical Oncology, vol. 10, Article ID 1758835918764628, 2018.

[6] V. A. Brentville, S. Atabani, K. Cook, and L. G. Durrant, "Novel tumour antigens and the development of optimal vaccine design," Therapeutic Advances in Vaccines and Immunotherapy, vol. 6, no. 2, pp. 31-47, 2018.

[7] S. H. Van Der Burg, R. Arens, F. Ossendorp, T. Van Hall, and C. J. M. Melief, "Vaccines for established cancer: Overcoming the challenges posed by immune evasion," Nature Reviews Cancer, vol. 16, no. 4, pp. 219-233, 2016.

[8] S. Gujar, J. G. Pol, and G. Kroemer, "Heating it up: oncolytic viruses make tumors 'hot' and suitable for checkpoint blockade immunotherapies," Oncoimmunology, vol. 7, no. 8, Article ID e1442169, 2018. 
[9] R. Huber, M. Rostock, R. Goedl et al., "Mistletoe treatment induces GM-CSF- and IL-5 production by PBMC and increases blood granulocyte- and eosinophil counts: a placebo controlled randomized study in healthy subjects," European Journal of Medical Research, vol. 10, no. 10, pp. 411-418, 2005.

[10] R. Huber, H. Lüdtke, J. Wieber, and C. Beckmann, "Safety and effects of two mistletoe preparations on production of Interleukin- 6 and other immune parameters - a placebo controlled clinical trial in healthy subjects," BMC Complementary and Alternative Medicine, vol. 11, no. 116, 2011.

[11] R. Klein, K. Classen, P. A. Berg, R. Lüdtke, M. Werner, and R. Huber, "In vivo-induction of antibodies to mistletoe lectin1 and viscotoxin by exposure to aqueous mistletoe extracts: a randomised double-blinded placebo controlled phase I study in healthy individuals," European Journal of Medical Research, vol. 7, no. 4, pp. 155-163, 2002.

[12] T. Hajto, K. Hostanska, K. Frei, C. Rordorf, and H.-J. Gabius, "Increased secretion of tumor necrosis factors alpha, interleukin 1 , and interleukin 6 by human mononuclear cells exposed to beta-galactoside-specific lectin from clinically applied mistletoe extract," Cancer Research, vol. 50, no. 11, pp. 33223326, 1990.

[13] A. Büssing, A. Rosenberger, C. Stumpf, and M. Schietzel, "Development of lymphocyte subsets in tumor patients after subcutaneous administration of mistletoe extracts," Forsch Komplementarmed, vol. 6, no. 4, pp. 196-204, 1999.

[14] J. Beuth, H. L. Ko, H. Gabius, H. Burrichter, K. Oette, and G. Pulverer, "Behavior of lymphocyte subsets and expression of activation markers in response to immunotherapy with galactoside-specific lectin from mistletoe in breast cancer patients," The Clinical Investigator, vol. 70, no. 8, pp. 658-661, 1992.

[15] T. Hajto, "Immunomodulatory effects of iscador: a Viscum album preparation," Oncology, vol. 43, no. 1, pp. 51-65, 1986.

[16] O. Podlech, P. N. Harter, M. Mittelbronn, S. Pöschel, and U. Naumann, "Fermented mistletoe extract as a multimodal antitumoral agent in gliomas," Evidence-Based Complementary and Alternative Medicine, vol. 2012, Article ID 501796, 15 pages, 2012.

[17] J. Tabiasco, F. Pont, J. Fournié, and A. Vercellone, "Mistletoe viscotoxins increase natural killer cell-mediated cytotoxicity," European Journal of Biochemistry, vol. 269, no. 10, pp. 25912600, 2002.

[18] T. J. Yoon, Y. C. Yoo, T. B. Kang et al., "Cellular and humoral adjuvant activity of lectins isolated from Korean mistletoe (Viscum album colaratum)," International Immunopharmacology, vol. 1, no. 5, pp. 881-889, 2001.

[19] M. B. Enesel, I. Acalovschi, V. Grosu et al., "Perioperative application of the Viscum album extract Isorel in digestive tract cancer patients," Anticancer Reseach, vol. 25, no. 6 C, pp. 45834590, 2005.

[20] A. Büssing, M. Bischof, W. Hatzmann et al., "Prevention of surgery-induced suppression of granulocyte function by intravenous application of a fermented extract from Viscum album L. in breast cancer patients," Anticancer Reseach, vol. 25, no. 6C, pp. 4753-4757, 2005.

[21] M. Schink, W. Tröger, A. Dabidian et al., "Mistletoe extract reduces the surgical suppression of natural killer cell activity in cancer patients. A randomized phase III trial," Forschende Komplementärmedizin, vol. 14, no. 1, pp. 9-17, 2007.
[22] J.-J. Kim, Y.-H. Hwang, K.-Y. Kang et al., "Enhanced dendritic cell maturation by the B-chain of Korean mistletoe lectin (KMLB), a novel TLR4 agonist," International Immunopharmacology, vol. 21, no. 2, pp. 309-319, 2014.

[23] C. Steinborn, A. M. Klemd, A. S. Sanchez-Campillo et al., "Viscum album neutralizes tumor-induced immunosuppression in a human in vitro cell model," PloS One, vol. 12, no. 7, Article ID e0181553, 2017.

[24] M. A. Horneber, G. Bueschel, R. Huber, K. Linde, and M. Rostock, "Mistletoe therapy in oncology," Cochrane Database of Systematic Reviews, vol. 2, Article ID CD003297, 2008.

[25] M. Evans, S. Bryant, A. L. Huntley, and G. Feder, "Cancer patients' experiences of using mistletoe (Viscum album): a qualitative systematic review and synthesis," The Journal of Alternative and Complementary Medicine (New York, N.Y.), vol. 22, no. 2, pp. 134-144, 2016.

[26] G. S. Kienle and H. Kiene, "Review article: influence of viscum album L (European mistletoe) extracts on quality of life in cancer patients: a systematic review of controlled clinical studies," Integrative Cancer Therapies, vol. 9, no. 2, pp. 142-157, 2010.

[27] S. Elluru, J.-P. D. Van Huyen, S. Delignat et al., "Molecular mechanisms underlying the immunomodulatory effects of mistletoe (Viscum album L.) extracts Iscador," ArzneimittelForschung/Drug Research, vol. 56, no. 6A, pp. 461-466, 2006.

[28] D. Ortuño-Sahagún, K. Zänker, A. K. S. Rawat, S. V. Kaveri, and P. Hegde, "Natural Immunomodulators," Journal of Immunology Research, vol. 2017, Article ID 7529408, 2 pages, 2017.

[29] C.-Y. Chen, C.-L. Kao, and C.-M. Liu, “The cancer prevention, anti-inflammatory and anti-oxidation of bioactive phytochemicals targeting the TLR4 signaling pathway," International Journal of Molecular Sciences, vol. 19, no. 9, 2018.

[30] P. Hegde, M. S. Maddur, A. Friboulet, J. Bayry, and S. V. Kaveri, "Viscum album exerts anti-inflammatory effect by selectively inhibiting cytokine-induced expression of cyclooxygenase-2," PLoS ONE, vol. 6, no. 10, Article ID e26312, 2011.

[31] M. K. Kim, K. J. Yun, D. H. Lim, J. Kim, and Y. P. Jang, "Anti-inflammatory properties of flavone di-C-Glycosides as active principles of camellia mistletoe, korthalsella japonica," Biomolecules \& Therapeutics, vol. 24, no. 6, pp. 630-637, 2016.

[32] C. Saha, P. Hegde, A. Friboulet, J. Bayry, and S. V. Kaveri, "Viscum album-mediated COX-2 inhibition implicates destabilization of COX-2 mRNA," PLoS ONE, vol. 10, no. 2, Article ID e0114965, 2015.

[33] A. Greenhough, H. J. M. Smartt, A. E. Moore et al., "The COX2/PGE2 pathway: key roles in the hallmarks of cancer and adaptation to the tumour microenvironment," Carcinogenesis, vol. 30, no. 3, pp. 377-386, 2009.

[34] Y. Hatano, H. Matsuoka, L. Lam, and D. C. Currow, "Side effects of corticosteroids in patients with advanced cancer: a systematic review," Supportive Care in Cancer: Official Journal of the Multinational Association of Supportive Care in Cancer, vol. 26, no. 12, pp. 3979-3983, 2018.

[35] L. J. Marnett, "The COXIB experience: a look in the rearview mirror," Annual Review of Pharmacology and Toxicology, vol. 49, pp. 265-290, 2009.

[36] C. Cerella, C. Sobolewski, M. Dicato, and M. Diederich, "Targeting COX-2 expression by natural compounds: a promising alternative strategy to synthetic COX-2 inhibitors for cancer chemoprevention and therapy," Biochemical Pharmacology, vol. 80, no. 12, pp. 1801-1815, 2010. 
[37] P. R. Bock, J. Hanisch, H. Matthes, and K. S. Zänker, “Targeting inflammation in cancer-related-fatigue: A rationale for mistletoe therapy as supportive care in colorectal cancer patients," Inflammation \& Allergy - Drug Targets, vol. 13, no. 2, pp. 105111, 2014.

[38] S. R. Elluru, C. Saha, P. Hedge, A. Friboulet, J. Bayry, and S. V. Kaveri, "Dissecting the Anti-Inflammatory effects of viscum album," in Mistletoe: From Mythology to Evidence-Based Medicine, K. S. Zänker and S. V. Kaveri, Eds., vol. 42015, pp. 6773, 2015.

[39] L. Spain, S. Diem, and J. Larkin, "Management of toxicities of immune checkpoint inhibitors," Cancer Treatment Reviews, vol. 44, pp. 51-60, 2016.

[40] M. Tocut, R. Brenner, and G. Zandman-Goddard, "Autoimmune phenomena and disease in cancer patients treated with immune checkpoint inhibitors," Autoimmunity Reviews, vol. 17, no. 6, pp. 610-616, 2018.

[41] C. F. Friedman, T. A. Proverbs-Singh, and M. A. Postow, "Treatment of the immune-related adverse effects of immune checkpoint inhibitors: a review," JAMA Oncology, vol. 2, no. 10, pp. 1346-1353, 2016.

[42] M. E. Valsecchi, "Combined nivolumab and ipilimumab or monotherapy in untreated melanoma," The New England Journal of Medicine, vol. 373, no. 13, pp. 1270-1271, 2015.

[43] N. A. Rizvi, M. D. Hellmann, J. R. Brahmer et al., "Nivolumab in combination with platinum-based doublet chemotherapy for first-line treatment of advanced non-small-cell lung cancer," Journal of Clinical Oncology: Official Journal of the American Society of Clinical Oncology, vol. 34, no. 25, pp. 2969-2979, 2016.

[44] G. S. Kienle, R. Grugel, and H. Kiene, "Safety of higher dosages of Viscum album L. in animals and humans-systematic review of immune changes and safety parameters," BMC Complementary and Alternative Medicine, vol. 11, article 72, 2011.

[45] M. L. Steele, J. Axtner, A. Happe, M. Kröz, H. Matthes, and F. Schad, "Adverse drug reactions and expected effects to therapy with subcutaneous mistletoe extracts (Viscum album L.) in cancer patients," Evidence-Based Complementary and Alternative Medicine, vol. 2014, Article ID 724258, 11 pages, 2014.

[46] M. L. Steele, J. Axtner, A. Happe, M. Kröz, H. Matthes, and F. Schad, "Safety of intravenous application of mistletoe (Viscum album L.) preparations in oncology: an observational study," Evidence-Based Complementary and Alternative Medicine, vol. 2014, Article ID 236310, 10 pages, 2014.

[47] M. L. Steele, J. Axtner, A. Happe, M. Kröz, H. Matthes, and F. Schad, "Use and safety of intratumoral application of European mistletoe (Viscum album L) preparations in oncology," Integrative Cancer Therapies, vol. 14, no. 2, pp. 140-148, 2015.

[48] G. S. Kienle, M. Mussler, D. Fuchs, and H. Kiene, "Intravenous mistletoe treatment in integrative cancer care: a qualitative study exploring the procedures, concepts, and observations of expert doctors," Evidence-Based Complementary and Alternative Medicine, vol. 2016, Article ID 4628287, 16 pages, 2016.

[49] G. Bar-Sela, M. Wollner, L. Hammer, A. Agbarya, E. Dudnik, and N. Haim, "Mistletoe as complementary treatment in patients with advanced non-small-cell lung cancer treated with carboplatin-based combinations: a randomised phase II study," European Journal of Cancer, vol. 49, no. 5, pp. 1058-1064, 2013.

[50] A. Thronicke, S. Oei, A. Merkle, H. Matthes, and F. Schad, "Clinical safety of combined targeted and viscum album L. therapy in oncological patients," Medicines (Basel, Switzerland), vol. 5, no. 3, p. 100, 2018.
[51] A. Thronicke, M. L. Steele, C. Grah, B. Matthes, and F. Schad, "Clinical safety of combined therapy of immune checkpoint inhibitors and Viscum album L. therapy in patients with advanced or metastatic cancer," BMC Complementary and Alternative Medicine, vol. 17, no. 1, article 534, 2017.

[52] A. Thronicke, S. L. Oei, C. Grah, B. Matthes, and F. Schad, "Nivolumab-induced toxicity profile in patients with advanced or metastasized lung cancer treated with Viscum album L. extracts," in Proceedings of the German Cancer Congress, DKK2018, 2018.

[53] W. Tröger, D. Galun, M. Reif, A. Schumann, N. Stanković, and M. Milićević, "Viscum album [L.] extract therapy in patients with locally advanced or metastatic pancreatic cancer: a randomised clinical trial on overall survival," European Journal of Cancer (Oxford, England: 1990), vol. 49, no. 18, pp. 3788-3797, 2013.

[54] J. Axtner, M. Steele, M. Kröz, G. Spahn, H. Matthes, and F. Schad, "Health services research of integrative oncology in palliative care of patients with advanced pancreatic cancer," BMC Cancer, vol. 16, no. 579, 2016.

[55] F. Schad, A. Thronicke, M. L. Steele et al., "Overall survival of stage IV non-small cell lung cancer patients treated with Viscum album L. In addition to chemotherapy, a real-world observational multicenter analysis," PLoS ONE, vol. 13, no. 8, Article ID e0203058, 2018. 


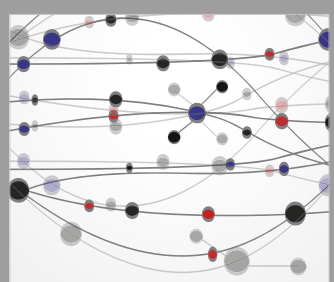

The Scientific World Journal
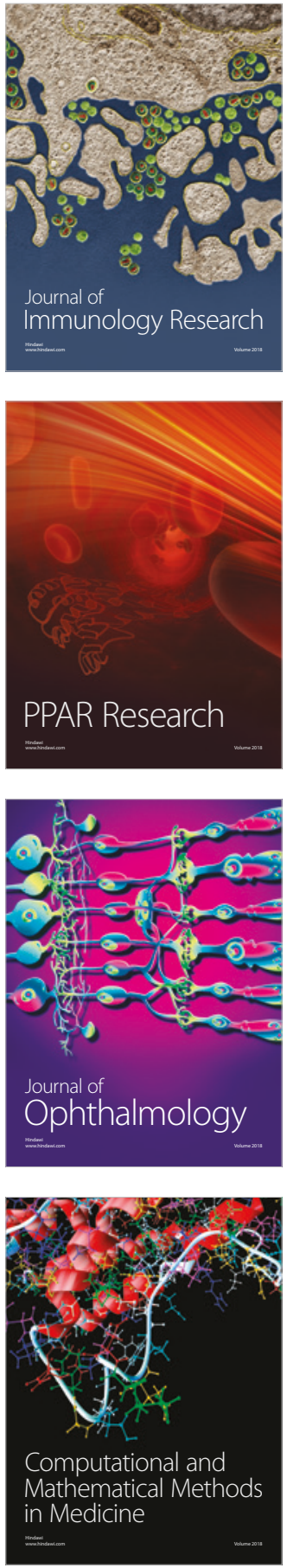

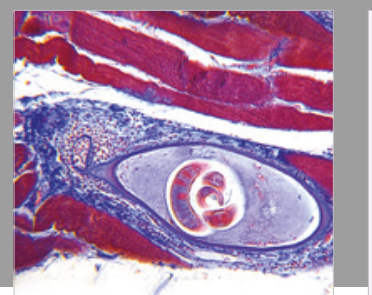

Gastroenterology Research and Practice

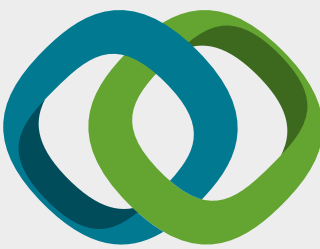

\section{Hindawi}

Submit your manuscripts at

www.hindawi.com
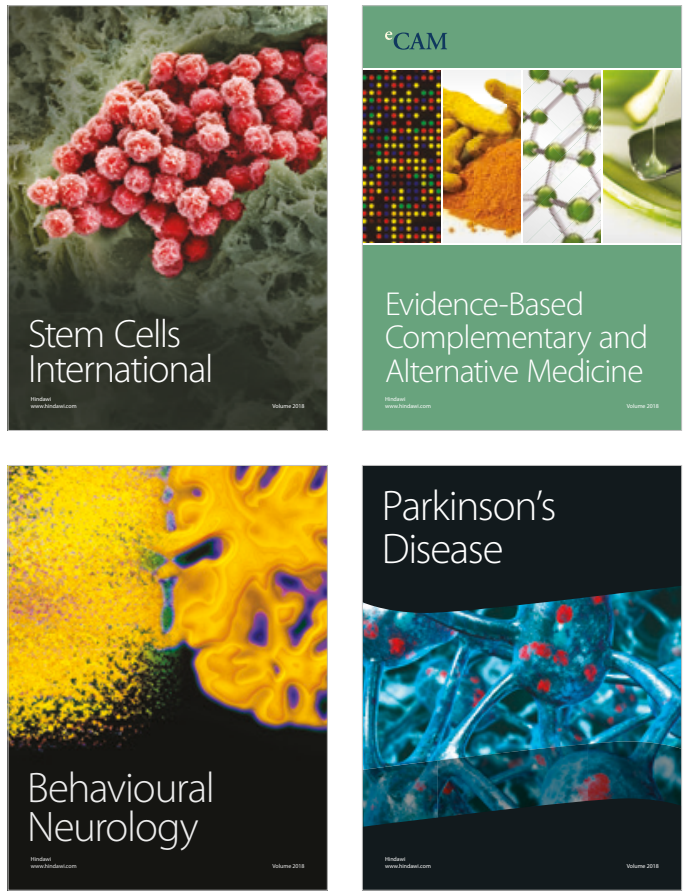

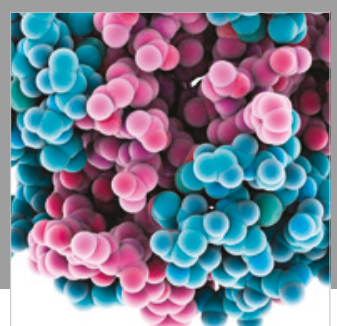

ournal of

Diabetes Research

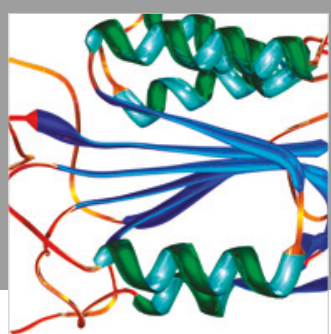

Disease Markers
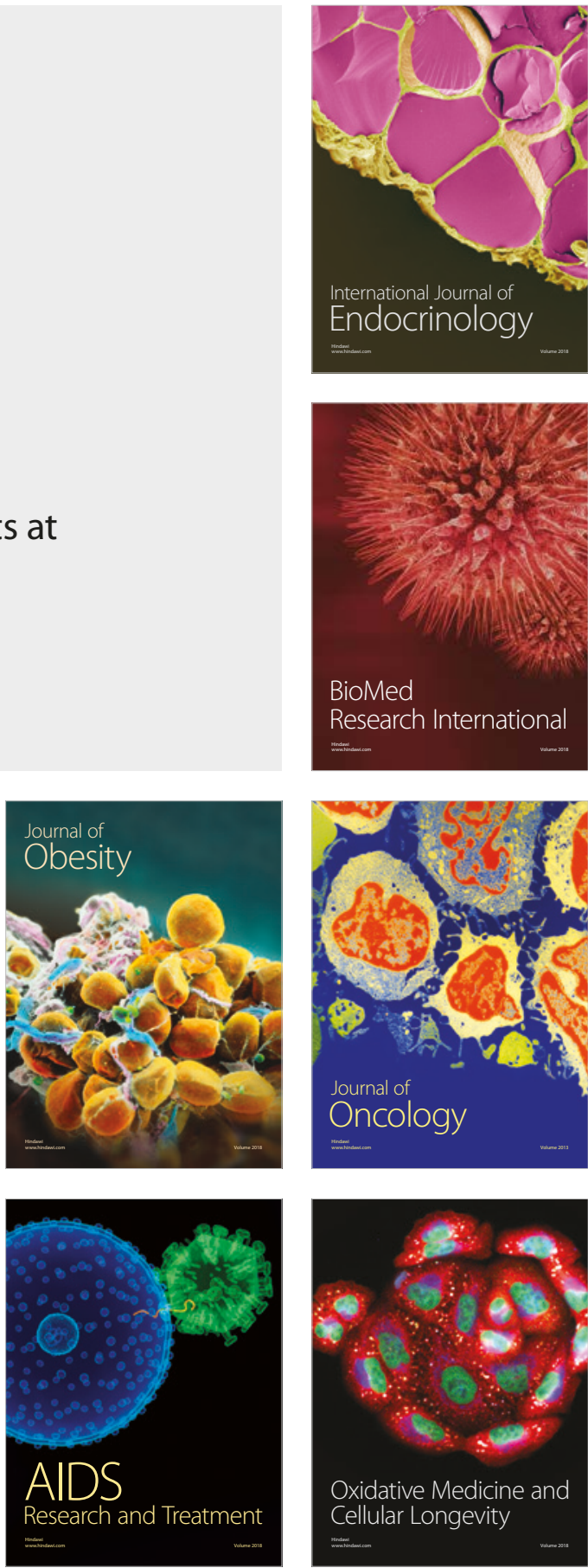